Dochead : Transplantation : nouvelles formes de rejets aigus du greffon rénal

\title{
Immunofluorescence multiparamétrique in situ : vers l'amélioration du phénotype de l'infiltrat cellulaire au cours du rejet d'allogreffe rénale
}

In situ multiplex immunofluorescence analysis of the inflammatory burden in kidney allograft rejection: a new tool to characterize the alloimmune response

Marion Rabant ${ }^{1 *, 2,3,4}$, Julien Calvani, ${ }^{1,5}$ Megumi Terada, ${ }^{5,6}$ Corinne Lesaffre, ${ }^{5}$ Jean-Paul Duong Van Huyen, ${ }^{1,3,4,5}$ et Patrick Bruneval, ${ }^{3,5,6}$

${ }^{1}$ Laboratoire d'anatomie et cytologie pathologiques, hôpital Necker-Enfants-Malades, 149 rue de Sèvres, 75015 Paris, France.

${ }^{2}$ Inserm, U1151, institut Necker-Enfants-Malades, 149 rue de Sèvres, 75015 Paris, France.

${ }^{3}$ Université Paris Descartes, Sorbonne Paris Cité, 12, rue de l'École-de-Médecine, 75006 Paris, France.

${ }^{4}$ Paris Translational Research Center for Organ Transplantation, hôpital européen Georges-Pompidou, 20 rue Leblanc, 75015 Paris, France

${ }^{5}$ Inserm, UMR-S970, 20 rue Leblanc, 75015 Paris, France

${ }^{6}$ Laboratoire d'anatomie et cytologie pathologiques, hôpital européen Georges-Pompidou, 20 rue Leblanc, 75015 Paris, France

*Auteur correspondant : Dr Marion Rabant ; e-mail: marion.rabant@aphp.fr 


\section{Résumé}

Contexte.- Le diagnostic du rejet en transplantation rénale est histologique avec, pour le rejet cellulaire, la présence de cellules inflammatoires dans l'interstitium rénal avec lésions de tubulite, et, pour le rejet humoral, la présence de cellules inflammatoires dans les capillaires glomérulaires et péritubulaires. La composition exacte de l'infiltrat et sa localisation précise sont difficiles à analyser sur une même lame de biopsie. Nous avons voulu tester une nouvelle technique d'immunofluorescence multiparamétrique réalisable sur biopsies fixées pour détecter jusqu'à quatre types cellulaires sur la même lame.

Méthodes.- Par technique d' immunofluorescence multiparamétrique, nous avons marqué les cellules NK, les macrophages, les lymphocytes T et les cellules endothéliales à l'aide des anticorps antiNKP46, CD163, CD3 et CD34 respectivement, au sein de 20 biopsies de rejet humoral, 20 biopsies de rejet cellulaire et cinq biopsies normales. Les images ont ensuite été scannées et les cellules quantifiées de manière automatique, et leur localisation intra- ou extravasculaire déterminée. Parallèlement, nous avons marqué et quantifié les cellules NK avec l'anticorps anti NKP46 par technique d'immunohistochimie classique et également quantifié les transcrits relatifs aux cellules NK, lymphocytes $\mathrm{T}$ et macrophages à partir de 26 biopsies congelées par polymerase chain reaction quantitative en temps réel.

Résultats.- La quantification des cellules NK par technique d' immunohistochimie classique était significativement corrélée à la quantification automatique par technique d' immunofluorescence multiparamétrique $(r=0,91, p<0,001)$. En outre, la quantification des cellules $\mathrm{NK}$, lymphocytes $\mathrm{T}$ et macrophages par immunofluorescence multiparamétrique était également corrélée à l'expression des transcrits $(r>0,46, p<0,021)$. Par immunofluorescence multiparamétrique, les lymphocytes $\mathrm{T}$ et les macrophages étaient les deux populations cellulaires prédominantes impliquées dans le rejet ( $48,0 \pm 4,4 \%$ et $49,3 \pm 4,4 \%$ respectivement dans le rejet humoral; $51,8 \pm 6,0 \%$ et $45,3 \pm 5,8 \%$ dans le rejet cellulaire), bien que nous ayons constaté une répartition très hétérogène dans la composition cellulaire. Les cellules NK étaient rares à la fois dans le rejet cellulaire et dans le rejet humoral $(2,9 \pm 0,6 \%$ et $2,7 \pm 0,7 \%$ ), Le compartiment intravasculaire était composé principalement de lymphocytes $\mathrm{T}$, dans les deux types de rejet. Cependant la densité de cellules NK et de macrophages intravasculaire était plus importante dans le rejet humoral que dans le rejet cellulaire.

Conclusion.- L' immunofluorescence multiparamétrique est une technique fiable permettant l'étude précise de la composition cellulaire et sa localisation sur biopsies fixées et incluses en paraffine.

\section{Mots clefs}

transplantation rénale, immunofluorescence multiparamétrique, rejet humoral, rejet cellulaire, cellules NK 


\section{Summary}

Background.- The exact composition and localization of the inflammatory burden during allograft rejection is difficult to analyse on the same biopsy slide. We tested the feasibility of detecting four distinct markers in a same paraffin-embedded tissue section from human kidney allograft rejection by using an innovative process of multiplex immunofluorescence.

Methods-. Kidney allograft biopsies from 20 antibody-mediated rejection, $20 \mathrm{~T}$ cell-mediated rejection and five non rejection were labelled against NKp46, CD163, CD3, and CD34 respectively for NK cells, macrophages, $\mathrm{T}$ cells and endothelial cells. Images were scanned and cells were automatically quantified and their extra- or intravascular location determined. Conventional immunohistochemistry against NKp46 with manual quantification and real time quantitative polymerase chain reaction for evaluation of the relative messenger ribonucleic acid (mRNA) expression levels of NK, T cell and macrophage transcripts were simultaneously performed.

Results.- Multiplex immunofluorescence cell quantification was strongly correlated to manual quantification by immunohistochemistry $(r=0.91, p<0.001)$ and to mRNA expression levels $(r>0.46$, $\mathrm{p}<0.021)$. $\mathrm{T}$ cells and macrophages were the two predominant populations involved in rejection $(48.0 \pm 4.4 \%$ and $49.3 \pm 4.4 \%$ in antibody-mediated rejection; $51.8 \pm 6.0 \%$ and $45.3 \pm 5.8 \%$ in $\mathrm{T}$ cellmediated rejection respectively) despite an important heterogeneity in the composition of the inflammatory burden. NK cells constituted a rare population for both T cell-mediated rejection $(2.9 \pm 0.6 \%)$ and antibody-mediated rejection $(2.7 \pm 0.7 \%)$. The intravascular compartment was mainly composed of T cells, including during antibody-mediated rejection. However, NK cells and macrophages densities were significantly higher in capillaries during antibody-mediated rejection.

Conclusion.- Multiplex immunofluorescence staining is a reliable technology allowing studying the exact composition and localization of the inflammatory burden during kidney allograft rejection.

\section{Keywords}

multiplex immunofluorescence, antibody mediated rejection, T cell mediated rejection, NK cells

\section{Introduction}

\subsection{Mécanismes du rejet}

Les mécanismes du rejet d'allogreffe font intervenir dans un premier temps l'immunité innée non spécifique activée par les médiateurs pro-inflammatoires (radicaux oxydés, cytokines, chimiokines) induits lors de l'implantation de l'organe transplanté qui précède la réponse $\mathrm{T}$ adaptative. En réponse à ces signaux, les cellules dendritiques synthétisent alors des cytokines et chimiokines (interleukine [IL]-1, IL-12, tumour necrosis factor [TNF] $\alpha$, chemokine [C-C motif] ligand 9 [CCL9], etc.) permettant le recrutement de macrophages, polynucléaires neutrophiles, cellules NK qui vont infiltrer 
le greffon. Parallèlement, les cellules présentatrices d'antigène activées changent de phénotype et de fonction et expriment fortement le complexe majeur d'histocompatibilité de classe I ainsi que des molécules de costimulation (CD80, CD86, CD40) et des récepteurs membranaires. Elles migrent vers les organes lymphoïdes secondaires de drainage du receveur et viennent au contact des lymphocytes $\mathrm{T}$ présents et les activent via l'interaction de leur récepteur-complexe majeur d'histocompatibilité/peptide antigénique et les molécules de costimulation. Une réponse immune adaptative se développe ainsi dans un second temps : les lymphocytes $\mathrm{T}$ du receveur, qui reconnaissent les antigènes du donneur qui leur sont présentés, sont activés, prolifèrent et se différencient en cellules effectrices et envoient des signaux de croissance et de différenciation à d'autres types cellulaires jouant un rôle dans la réponse allo-immune. Les cellules effectrices quittent les ganglions pour rejoindre l'organe transplanté, par les vaisseaux, avec extravasation et diapédèse dans le tissu grâce aux molécules d'adhésion exprimées à la surface des cellules endothéliales.

Ainsi, histologiquement, le rejet cellulaire (T-cell mediated rejection, TCMR) est caractérisé par l'infiltration de cellules inflammatoires mononucléées dans l'interstitium, essentiellement des lymphocytes $\mathrm{T}$ et des monocytes-macrophages. Des lymphocytes B et des plasmocytes peuvent également être présents, recrutés de manière non spécifique. Les immunomarquages révèlent que les cellules infiltrantes sont principalement des cellules T, les cellules effectrices CD8 étant prédominantes. La classification de Banff, classification de référence en pathologie de la transplantation rénale, ne recommande pas de typer l'infiltrat et les critères diagnostiques du rejet cellulaire reposent sur l'étendue de l'infiltration, sur son agressivité caractérisée par la présence de lésions de tubulite et sur la présence de lésions d'artérite intimale au niveau des artères ${ }^{1}$.

Le rejet humoral (antibody-mediated rejection, ABMR), lié à la présence d'anticorps dirigés contre des antigènes du donneur présents sur l'endothélium, le plus souvent des molécules HLA, nécessite l'interaction entre cellules $B$ et $T$ spécifiques de l'antigène, au sein des structures lymphoïdes et l'initiation de centres germinatifs. Ces anticorps sont délétères par plusieurs mécanismes : l'activation de la cascade du complément aboutissant à la formation du complexe d'attaque membranaire et également à l'agression du greffon en attirant des cellules inflammatoires par le biais des anaphylatoxines $\mathrm{C} 3 \mathrm{a}$ et $\mathrm{C} 5 \mathrm{a}$. Les polynucléaires neutrophiles et les macrophages expriment en effet les récepteurs de surface pour C3a et C5a (CD88). L'activation du complément a également un effet sur l'activation des cellules endothéliales en augmentant leur production de molécules pro-inflammatoires (cytokines, chimiokines, molécules d'adhésion et facteurs de croissance). Les anticorps anti-HLA peuvent également avoir des effets pathogènes sur les cellules endothéliales indépendants de l'activation du complément. Ils peuvent ainsi induire l'activation des cellules endothéliales en l'absence de complément, notamment via les molécules HLA de classe I. Les anticorps peuvent également avoir un effet cytotoxique sur les cellules endothéliales par un mécanisme de cytotoxicité 
dépendante des anticorps en recrutant des cellules porteuses d'un récepteur de faible affinité au fragment Fc des immunoglobulines FcyRIII (CD16), les cellules NK et les macrophages.

Histologiquement, le rejet humoral est caractérisé principalement par la présence d'une inflammation microvasculaire (glomérulite et capillarite péritubulaire). Il peut s'y associer d'autres lésions histologiques telles que l'artérite intimale, la microangiopathie thrombotique ou encore la nécrose tubulaire aiguë. D'un point de vue histologique, seules les lésions d'artérite intimale et l'intensité de l'inflammation de la microcirculation ont été associées à un mauvais pronostic ${ }^{2,3}$. La classification de Banff ne recommande pas de préciser le type cellulaire présent dans les capillaires pour diagnostic de rejet humoral du greffon rénal.

\subsection{Composition de l'infiltrat au cours du rejet}

Peu d'équipes se sont intéressé à la composition précise de l'infiltrat au cours du rejet, qu'il soit cellulaire ou humoral. Le rôle central des lymphocytes $\mathrm{T}$ dans l'initiation du processus de rejet est établi. Cependant, le rôle des autres cellules (macrophages, cellules NK) est moins décrit. Au cours du rejet cellulaire, les macrophages peuvent représenter jusqu'à $60 \%$ des cellules inflammatoires ${ }^{4}$. Plusieurs études ont montré que la densité de macrophages pouvait avoir un impact défavorable sur la survie du greffon rénal. Ainsi, Bergler et al. se sont intéressés à la densité de macrophages au cours des différents types de rejet (rejet cellulaire avec ou sans artérite, rejet humoral) et leur localisation (glomérulaire, périvasculaire, péritubulaire) ${ }^{5}$ et ont montré que l'intensité de l'infiltration macrophagique prédisait la fonction rénale à 3 ans et la survie du greffon. Plus récemment, une équipe a quantifié sur des coupes sériées les lymphocytes T, B, macrophages et cellules dendritiques dans 67 biopsies de dépistage précoces à 6 semaines, dont $16 \%$ avaient des lésions de rejet essentiellement minime de type borderline. La densité de macrophages était le seul élément histologique prédictif de la fonction rénale et de la perte du greffon ${ }^{6}$.

Sicard et al. ont quantifiés sur coupes sériées avec analyse automatisée les macrophages, les lymphocytes B et $\mathrm{T}$ ainsi que les polynucléaires neutrophiles chez 52 patients avec diagnostic de rejet humoral. Là encore, seul le nombre de macrophages dans l'interstitium (et non dans les capillaires) était un prédicteur indépendant de perte du greffon, tandis que les scores d'inflammation de la classification de Banff ne l'étaient pas ${ }^{7}$.

Par ailleurs, ces dernières années, un intérêt particulier a été porté aux cellules NK principalement au cours du rejet humoral. En effet, en 2010, une étude transcriptomique réalisée à partir de biopsies de rejet humoral a permis de mettre en évidence la présence de transcrits dits «spécifiques » des cellules NK (en particulier MYBL1, KLRF1 [=NKp80], SH2D1B [=EAT2], CX3CR1, GNLY, et FGFBP2) ${ }^{8}$. Récemment, d'autres études ont confirmé ces observations au cours du rejet humoral en transplantation rénale et cardiaque. Les cellules NK semblent également être impliquées dans le rejet 
cellulaire. En 2012, il a été mis en évidence la présence de «transcrits NK» dans des biopsies rénales au cours du rejet cellulaire précoce (au cours de la première année post transplantation) ${ }^{9}$. De façon intéressante, cette même étude a montré que l'implication des cellules NK au cours du rejet humoral concernait surtout les cas de rejet humoral tardif (après 1 an de transplantation).

Les cellules NK sont impliquées dans la reconnaissance du greffon par deux mécanismes : d'une part, la cytotoxicité dépendante des anticorps et d'autre part, la théorie du missing self. Schématiquement, au cours de la cytotoxicité dépendante des anticorps, les cellules NK reconnaissent, par l'intermédiaire d'un récepteur Fc situé à leur membrane (FcgRIII ou CD16), les anticorps spécifiques du donneur fixés sur les cellules endothéliales du greffon. A la suite des signaux émis par le récepteur CD16, les cellules NK sont activées et déchargent leurs granules, qui contiennent des protéines capables de lyser les cellules cibles. De façon physiologique, l'activation des cellules NK résulte d'un équilibre entre la stimulation des récepteurs activateurs et celle des récepteurs inhibiteurs. Parmi les nombreux récepteurs NK, les récepteurs KIR peuvent être soit activateurs, soit inhibiteurs, en fonction de la longueur de leur domaine intracytoplasmique. Les récepteurs KIR reconnaissent les molécules du complexe majeur d'histocompatibilité de classe I. En situation normale, l'expression constitutive de molécules HLA de classe I à la surface des cellules saines délivre aux cellules NK des signaux inhibiteurs et empêche leur destruction par les NK. Lors d'une allogreffe, les différences d'antigènes HLA entre donneur et receveur peuvent induire une modification de la balance de signaux activateurs et inhibiteurs conduisant à l'activation des fonctions effectrices NK (c'est la théorie du missing self). L'incompatibilité KIR a en particulier été bien décrite en greffe de cellules souches hématopoïétiques et est responsable d'un effet antileucémique. En transplantation d'organe, une étude récente en allogreffe rénale chez l'homme a montré que l'incompatibilité KIR pourrait favoriser le rejet chronique ${ }^{10}$.

Un des écueils pour l'analyse in situ des cellules NK est l'absence de spécificité de certains marqueurs. La grande majorité des auteurs ont utilisé pour cela le CD56. Ainsi, il a par exemple été montré la présence de cellules CD56+ dans les capillaires péritubulaires rénaux au cours du rejet humoral. Toutefois, le CD56 est certes exprimé par les cellules NK, mais également par d'autres populations cellulaires comme les lymphocytes T $\alpha \beta$, les lymphocytes $T \gamma \delta$, les cellules dendritiques et les monocytes ${ }^{11}$. Le CD56 pris isolément manque de spécificité, et ne permet pas de conclure formellement sur la présence de cellules NK au cours du rejet. Pour notre étude, nous avons décidé d'utiliser un anticorps anti-NKp46 pour identifier les cellules NK. Ce marqueur apparait plus spécifique que le CD56 et surtout utilisable sur matériel fixé en formol ou AFA et inclus en paraffine.

Pour caractériser les infiltrats, les pathologistes utilisent le plus souvent des techniques d'immunohistochimie pour mettre en évidence un à deux antigènes, sur des coupes sériées, rendant difficile l'analyse précise de la composition cellulaire et de la localisation des cellules. C'est pourquoi 
les approches multiparamétriques ont été développées afin de détecter de multiples biomarqueurs sur la même lame. En particulier, une technique d'immunofluorescence multiparamétrique est disponible depuis quelques années, basée sur l'amplification su signal par la tyramide ${ }^{12}$. Cette technique a été jusqu'à maintenant principalement utilisée en pathologie tumorale ${ }^{13,14}$.

\subsection{Objectif}

L'objectif de notre étude était de mettre au point la technique d'immunofluorescence multiparamétrique sur biopsies fixées et incluses en paraffine afin de détecter et de localiser en intraou extravasculaire sur une même lame plusieurs types cellulaires (lymphocytes T, macrophages et cellules NK) au cours du rejet cellulaire et du rejet humoral en transplantation rénale.

\section{Matériel et méthodes}

\subsection{Population}

A partir des registres de l'hôpital universitaire Necker-Enfants-Malades et du CHU de Bordeaux, nous avons identifié 20 biopsies de rejet humoral actif « pur », 20 biopsies de rejet cellulaire «pur » et cinq biopsies normales.

Pour le rejet humoral «pur» les critères d'inclusion étaient la présence d'une inflammation de la microcirculation au moins modérée $(\mathrm{g}+\mathrm{cpt} \geq 2)$ associé à la présence d'anticorps spécifiques $\mathrm{du}$ donneur et/ou à la positivité du $\mathrm{C} 4 \mathrm{~d}$. Les biopsies avec une inflammation interstitielle supérieure à $10 \%$ du cortex (ti>0) étaient exclues.

Pour le rejet cellulaire "pur", les biopsies avec glomérulite et C4d positif étaient exclues.

\subsection{Immunohistochimie conventionnelle}

Les biopsies ont toutes été marquées manuellement avec l'anticorps anti-NKP46 par technique conventionnelle d'immunoperoxydase. L'anticorps primaire monoclonal anti-NKp46 humain (clone $8 \mathrm{E} 5 \mathrm{~B}$, dilution 1:4000, fourni par Innate Pharma19) a été incubé 1 heure à $+37^{\circ} \mathrm{C}$. Après lavage avec une solution phosphate-buffered saline (PBS), un anticorps secondaire antisouris biotinylé (dilution 1/400 dans du sérum de cheval 5\%) a été appliqué sur les coupes de tissu pendant 30 minutes à température ambiante. Les lames ont ensuite été lavées dans un tampon TRIS $(\mathrm{pH} 7,4)$ puis un complexe avidine-biotine-peroxydase (Vector Laboratories, Burlingame, CA, USA) (se liant à l'anticorps secondaire biotinylé) a été appliqué pendant 30 minutes à température ambiante. Après un nouveau lavage dans un tampon tris-(hydroxyméthyl)-aminométhane (TRIS, pH 7,4), le chromogène 3,3'-diaminobenzidine (DAB) a été incubé sur les coupes de tissu pendant 6 minutes en présence d' $\mathrm{H}_{2} \mathrm{O}_{2}$. Enfin, une contre-coloration a été réalisée par l'hématoxyline. Les cellules marquées ont été comptées manuellement au microscope optique en grossissement de 40 fois, sur la totalité de la surface biopsique, en précisant la localisation intra- ou extravasculaire de chaque cellule marquée. La 
surface biopsique a été mesurée à l'aide d'un scanner de lames (Hamamatsu) afin de déterminer la densité cellulaire (c'est-à-dire le nombre de cellules positives pour NKp46 par millimètre carré).

\subsection{Technique d'immunofluorescence multiparamétrique}

Cette technique d'immunofluorescence multiparamétrique permet de réaliser jusqu'à sept marquages sur une même lame de tissu fixé et inclus en paraffine, suivi par la quantification automatisée des différents types cellulaires marqués, par un logiciel d'analyse d'image après une période de machine learning. Le principe général repose sur la réalisation de cycles répétés d'immunofluorescence: au cours de chaque cycle, un anticorps primaire spécifique d'un antigène d'intérêt est appliqué sur les coupes tissulaires, puis est ajouté un anticorps secondaire anti-espèce de l'anticorps primaire sur lequel est conjuguée une peroxydase, puis enfin est ajouté le fluorophore Opal ${ }^{\mathrm{TM}}$ (PerkinElmer $\left.{ }^{\circledR}\right)$. Les fluorophores Opal ${ }^{\mathrm{TM}}$ sont conjugués à des molécules de tyramides, qui servent de substrat à la peroxydase. L'enzyme produit une «forme activée » des molécules de tyramides, qui se fixent alors de façon covalente au niveau du site antigénique. Ce procédé est appelé tyramide signal amplification (TSA) (ref $13 \mathrm{JC}$ ). A la fin de chaque cycle, un traitement par la chaleur au micro-onde permet d'enlever les anticorps primaire et secondaire résiduels. En revanche, le fluorophore reste fixé au niveau du site antigénique dans la mesure où la liaison covalente résiste au traitement par la chaleur. Un nouveau cycle peut ensuite être effectué en utilisant un anticorps primaire de la même espèce, sans chevauchement avec le marquage précédent puisque le premier anticorps primaire et le premier anticorps secondaire ont été dégradés par la chaleur du micro-onde.

Les lames sont ensuite entièrement scannées à l'aide d'un microscope doté d'une camera multispectrale (Vectra 3.0®, PerkinElmer®) (Figure 1a). L'analyse informatisée s'est effectuée à l'aide du logiciel InForm ${ }^{\circledR}$ Tissue Finder ${ }^{\mathrm{TM}}$ (PerkinElmer $\left.{ }^{\mathrm{TM}}\right)$. Ce logiciel d'intelligence artificielle permet de détecter, quantifier et localiser les cellules immunomarquées à partir d'un fichier image, en trois étapes : segmentation cellulaire, segmentation tissulaire et phénotypage cellulaire (Figure 1c).

La segmentation cellulaire se fait à l'aide du 4',6-diamidino-2-phénylindole (DAPI) qui marque tous les noyaux des cellules présentes dans la biopsie. La segmentation tissulaire (intra- ou extravasculaire) a été réalisée à partir d'un immunomarquage des cellules endothéliales à l'aide de l'anticorps anti CD34 (clone QBEnd-10, dilution 1:250, Dako). Enfin, pour le phénotypage cellulaire, nous avons marqué les cellules NK (clone 8E5B, dilution 1:4000, Innate Pharma), les macrophages à l'aide de l'anticorps anti CD 163 (clone 10D6, dilution 1:250, Leica biosystems), et les lymphocytes T à l'aide de l'anticorps anti CD3 (clone SP7, dilution 1:500, Thermo scientific) (Figure 1b) ${ }^{19}$.

\subsection{Extraction d'acide ribonucléique et de polymerase chain reaction quantitatives en temps réel}

Parmi les 45 biopsies, un fragment congelé était disponible pour 26 d'entre elles pour l'extraction des acides ribonucléiques messagers (ARNm) (11 rejets humoraux, 10 rejets cellulaires and cinq biopsies 
normales). Les ARN totaux ont été extraits à l'aide du kit miRNeasy Mini Kit (Qiagen). Les acides désoxyribonucléiques (ADN) complémentaires ont été obtenus à l'aide d'un mélange d'inhibiteur de RNAse, de dNTP mix, de Random Hexamer, de solution de $\mathrm{MgCl}_{2}$ et de MultiScribe Reverse Transcriptase (Thermofisher). L'expression des ARNm de NKp46 et KLRF1 (pour les cellules NK), $C D 3$ et $C D 25$ (pour les lymphocytes T), et $C D 14$ et $C D 16$ (pour les monocytes/macrophages) a été quantifiée par polymerase chain reaction (PCR) quantitative en temps réel sur un système ViiA7 RealTime associé au logiciel QuantStudio Real-Time PCR (Thermofisher). Les expressions des gènes ont été normalisées par rapport à des gènes rapporteurs (moyenne de GAPDH et $H P R T 1$, et $18 S$ ). La méthode du $\Delta \Delta \mathrm{Ct}$ a été utilisée pour calculer l'expression relative en utilisant les ARN totaux de rate comme référence (AM7970, ThermoFisher).

\subsection{Statistiques}

Les analyses statistiques ont été réalisées avec le logiciel RStudio, version 1.1.456. Les comparaisons de moyennes ont été faites à l'aide du test de Mann Whitney. les comparaisons de moyennes parmi trois groupes ont été faites en utilisant le test de Kruskal-Wallis. Les comparaisons de pourcentages ont été faites à l'aide du test de Fisher.

\section{Résultats}

\subsection{Population}

Nous avons inclus 45 biopsies provenant de 44 patients (Tableaux 1 et 2) : 20 rejets humoraux, 20 rejets cellulaires et cinq «non rejet ». Les biopsies ont été réalisées après un délai moyen de 27,6 \pm 7,3 mois après la transplantation, Le débit de filtration glomérulaire moyen au moment de la biopsie était de $41,3 \pm 3,6 \mathrm{ml} / \mathrm{min} / 1,73 \mathrm{~m}^{2}$, Le nombre moyen de glomérules et la surface étaient respectivement de 11,3 $\pm 0,9$ et de 4,7 $\pm 0,3 \mathrm{~mm}^{2}$ et étaient comparables entre les trois groupes. La durée moyenne de suivi a été de 53,6 7,8 mois. Au cours du suivi, un patient est décédé et cinq patients ont perdu leur greffon. Toutes les pertes de greffon ont été attribuées au rejet.

\subsection{Immunofluorescence multiparamétrique : une technique fiable pour étudier la réponse allo- immune au cours du rejet}

Nous avons donc mis au point la technique d' immunofluorescence multiparamétrique sur biopsies en paraffine et quantifié les cellules NK, les lymphocytes T et les macrophages. Nous avons également marqué les cellules endothéliales afin de pouvoir localiser les cellules en situation intra- ou extravasculaire de façon automatisée.

Pour valider cette stratégie, nous avons quantifié manuellement les cellules NK après technique d'immunohistochimie classique avec l'anticorps anti-NKp46 (Figure 2a) et quantifié les niveaux 
d'expression des ARNm des cellules NK (NKP46 et KLRF1), des lymphocytes T (CD25 et CD3) et des macrophages (CD14 et CD16).

Nous avons trouvé une forte corrélation positive pour la quantification des cellules NK entre l' immunofluorescence multiparamétrique et l' immunohistochimie $(r=0,91, p<0,001)$ (Figure 2b).

Nous avons également corrélé les densités cellulaires mesurées par immunofluorescence multiparamétrique avec les scores de Banff : la densité des cellules NK, lymphocytes T et macrophages extravasculaires était corrélée à l'inflammation totale et à la tubulite. En outre, la densité des cellules NK et des macrophages intravasculaire était corrélée avec le score de glomérulite et de capillarite péritubulaire (Figure 2c)

Pour finir, les densités cellulaires mesurées par immunofluorescence multiparamétrique étaient également corrélées avec le niveau d'expression relative des ARNm quantifiés (coefficient $r$ entre 0,47 et 0,61 , valeurs de $p$ entre 0,001 et 0,021 ) (Figure 2d).

\subsection{Recrutement des macrophages, lymphocytes $T$ et cellules $N K$ pendant le rejet aigu du greffon rénal}

Par technique d' immunofluorescence multiparamétrique, nous avons pu constater que la densité cellulaire totale était faible dans les biopsies sans rejet $\left(45,79 \pm 19,6 / \mathrm{mm}^{2}\right)$ et qu'elle était significativement plus élevée au cours du rejet humoral $\left(435,1 \pm 70,1 / \mathrm{mm}^{2}\right)$ et du rejet cellulaire $\left(1303,2 \pm 254,3 / \mathrm{mm}^{2}\right)$, avec une différence significative entre les deux types de rejet, le rejet cellulaire comptant significativement plus de cellules $(\mathrm{p}=0,003)$ (Figure 3b). Il en était de même pour les trois types cellulaires considérés séparément, en particulier la densité des cellules NK était significativement plus élevée au cours du rejet cellulaire que du rejet humoral $\left(31,7 \pm 7,8 / \mathrm{mm}^{2}\right.$ contre $9,6 \pm 2,2 / \mathrm{mm}^{2}, p=0,01$ ) (Figure 3b).

En termes de proportions cellulaires, les lymphocytes $\mathrm{T}$ et les macrophages étaient les deux types cellulaires prédominants, que ce soit dans le rejet humoral ou cellulaire $(51,8 \pm 6,0 \%$ et $45,3 \pm 5,8 \%$ respectivement dans le rejet cellulaire; $48,0 \pm 4,4 \%$ et $49,3 \pm 4,4 \%$ respectivement dans le rejet humoral) (Figure 3c), A l'inverse, les cellules NK étaient rares $(0,6 \pm 0,4 \%$ des cellules dans les biopsies sans rejet, $2,7 \pm 0,7 \%$ au cours du rejet humoral et 2,9 $\pm 0,6 \%$ au cours du rejet cellulaire)

(Figure 3c).

\subsection{Différence de composition cellulaire entre les compartiments intra- et extravasculaire}

Après une période d'éducation du logiciel à distinguer les compartiments intra- et extravasculaire à l'aide du marquage CD34, le logiciel d'analyse d'image était capable de localiser chaque cellule (Figures 4a et 4b). 
Les lymphocytes $\mathrm{T}$ et les macrophages étaient les deux types cellulaires principaux présents dans le compartiment interstitiel à la fois pour le rejet cellulaire (CD3: 708,1 $\pm 207,2 / \mathrm{mm}^{2}$; CD163: 456,2 $\pm 89,3 / \mathrm{mm}^{2}$ ) et pour le rejet humoral (CD3:108,2 $\pm 26,8 / \mathrm{mm}^{2}$; CD163: 205,5 $\pm 45,8 / \mathrm{mm}^{2}$ ) (Figure 4c). En termes de proportions, lymphocytes T et macrophages représentaient $49,8 \pm 5,9 \%$ et $47,3 \pm 5,7 \%$ de l'ensemble des cellules dans l'interstitium au cours du rejet cellulaire et $32,9 \pm 4,0 \%$ et $65,4 \pm 4,0 \%$ respectivement au cours du rejet humoral dans le comparticment extravasculaire (Figure 4d).

Dans le compartiment intravasculaire, les lymphocytes $\mathrm{T}$ représentaient la population prédominante pour les deux types de rejet $\left(102,3 \pm 27,6 / \mathrm{mm}^{2}\right.$ soit $89,4 \pm 2,6 \%$ des cellules dans le rejet cellulaire et $97,3 \pm 17,9 / \mathrm{mm}^{2}$ soit 79,3 $\pm 3,8 \%$ des cellules pour le rejet cellulaire) (Figure 4e). Cependant, de façon intéressante, les densités cellulaires intravasculaires des cellules NK et des macrophages étaient significativement plus importantes dans le rejet humoral que dans le rejet cellulaire $\left(5,0 \pm 1,2 / \mathrm{mm}^{2}\right.$ contre $1,5 \pm 0,5 / \mathrm{mm}^{2}$ pour les cellules $\mathrm{NK}(\mathrm{p}=0,006)$ et $14,5 \pm 3,1 / \mathrm{mm}^{2}$ contre $5,0 \pm 1,5 / \mathrm{mm}^{2}$ pour les macrophages $(\mathrm{p}=0,013))$ (Figure 4e).

Nous avons observé beaucoup plus de cellules dans le comparticment extravasculaire que dans le compartiment intravasculaire, non seulement dans le rejet cellulaire $\left(1194,5 \pm 234,7 / \mathrm{mm}^{2}\right.$ contre 108,7 $\left.\pm 28,0 / \mathrm{mm}^{2}, p<0,001\right)$, mais également dans le rejet humoral $\left(318,3 \pm 62,9 / \mathrm{mm}^{2}\right.$ contre 116,8 $\pm 18,4 / \mathrm{mm}^{2}, p=0,012$ ), malgré le fait que nous ayons inclus des cas de rejets humoraux "purs" c'est à dire sans inflammation interstitielle significative. En termes de proportions, 92,6 $\pm 1,6 \%$ des cellules inflammatoires étaient retrouvées dans l'interstitium au cours du rejet cellulaire, alors que 67,4 $\pm 4,1 \%$ y étaient retrouvées dans le rejet humoral. A l'inverse, et de façon attendue, la proportion de cellules intravasculaires dans le rejet humoral était plus élevée que dans le rejet cellulaire $(32,6 \pm 4,1 \%$ contre $7,4 \pm 1,6 \%, p<0,001)$.

\subsection{Une composition cellulaire très hétérogène au cours du rejet}

Nous avons observé une hétérogénéité très importante dans la composition cellulaire que ce soit au cours du rejet cellulaire ou du rejet humoral. En effet, la balance entre la proportion de lymphocytes et de macrophages variait beaucoup d'un patient à l'autre. Par exemple, la proportion de lymphocytes T pouvait varier de 10,0 à $92,7 \%$ dans le rejet cellulaire et de 9,9 à $81,0 \%$ dans le rejet humoral, tandis que ces variations pour les macrophages pouvaient aller de 7,0 à 89,0\% dans le rejet cellulaire et de,8 à 87,7\% pour le rejet humoral (Figures 5a and 5b). Ces situations extrêmes sont illustrées dans la

\section{Figure 5c.}

Nous avons comparé les données cliniques, biologiques et histologiques entre les biopsies de rejet "riches" et "pauvres" en chaque type cellulaire, en se basant sur la valeur médiane de chaque type cellulaire pour distinguer ces groupes (soit $44,4 \%$ pour les macrophages, $53,0 \%$ pour les lymphocytes 
T et 2,1\% pour les cellules NK) Nous n'avons trouvé aucune différence entre ces groupes, probablement du fait de la petite taille des effectifs.

\section{Discussion}

Nous avons démontré la faisabilité de cette technique d'immunofluorescence multiparamétrique pour la détection de quatre marqueurs distincts, dans le contexte de la transplantation rénale, sur des lames fixées et incluses en paraffine. Nous avons montré que cette technique était fiable et corrélée à la technique d'immunohistochimie conventionnelle et au niveau d'expression génique des différents types cellulaires par PCR en temps réel. En outre, une analyse automatisée par un logiciel d'analyse d'image a permis une quantification et une localisation précise et reproductible des différents types cellulaires. Cette technique semble être un complément très intéressant aux techniques moléculaires d'analyse des transcrits, puisqu'elle permet d'analyser in situ le phénotype de chaque cellule et de décrire la morphologie tissulaire et l'interaction cellulaire sur une même lame de biopsie.

Nous avons ainsi pu montrer que les lymphocytes $\mathrm{T}$ et les macrophages représentaient les principaux types cellulaires impliqués au cours du rejet cellulaire et humoral avec cependant une grande hétérogénéité. Les cellules NK étaient également présentes au cours du rejet mais elles représentaient un petit contingent, autour de $3 \%$ des cellules.

Cette faible proportion contraste avec le rôle important qui a été attribué aux cellules NK au cours des dernières années, notamment au cours du rejet humoral. Hidalgo et al ont en effet observé une expression élevée du set de transcrits liés à l'activation des cellules NK (CX3CR1, MYBL1, FGFBP2, KLRF1, SH2D1B and GNLY) au cours du rejet humoral ${ }^{8,9}$. Cette contradiction apparente entre leur faible proportion et leur grande importance peut s'expliquer en partie par le rôle central des cellules NK dans la production des cytokines et des chimiokines et leur interaction avec les autres cellules de l'immunité. Cependant, une autre explication pourrait être la non spécificité de certains transcrits dits «NK ». En effet, certains de ces transcrits, comme CX3CR1 et GNLY, ne sont pas spécifiques des cellules NK et ont également été décrits comme surexprimés dans les monocytes et les lymphocytes T activés, dans une étude de single-cell RNA au cours d'un rejet mixte ${ }^{15}$. Dans cette étude, qui a évalué 8746 transcriptomes cellulaires, aucune cellule NK n'a été mise en évidence ${ }^{15}$.

Malgré leur faible proportion, les cellules NK étaient cependant plus nombreuses au sein du compartiment intravasculaire, de même que les macrophages, au cours du rejet humoral. Cette augmentation va dans le sens du recrutement possible des cellules NK au cours du rejet humoral par des mécanismes indépendants du complément, notamment via la voie de la cytotoxicité dépendante des anticorps ${ }^{16}$.

Grace à cette étude, nous avons été en mesure de localiser les cellules de façon précise. De façon intéressante, nous avons retrouvé de très nombreuses cellules interstitielles au cours du rejet humoral, 
ce qui est en accord avec d'autres études en transplantation rénale mais également cardiaque et ce qui rend compte de la difficulté de visualiser et de localiser précisément l'ensemble des cellules ${ }^{7,17}$. En outre, alors que le compartiment interstitiel était composé majoritairement de macrophages et de lymphocytes, cette étude a montré que les lymphocytes T représentaient la population principale dans le compartiment intravasculaire. Ce résultat est cohérent avec une étude phénotypique antérieure en transplantation cardiaque, où Fedrigo et al ont également retrouvé une majorité de lymphocytes $\mathrm{T}$ intravasculaires au cours du rejet humoral cardiaque ${ }^{17}$. Ces résultats soulèvent la question du rôle des lymphocytes $\mathrm{T}$ dans la physiopathologie du rejet humoral ${ }^{16}$.

Enfin, il apparaît qu'il existe une très grande hétérogénéité dans la composition cellulaire, que ce soit au cours du rejet cellulaire ou au cours du rejet humoral, avec des rejets très riches en lymphocytes et d'autres très riches en macrophages. Cette hétérogénéité pourrait avoir une importance en terme de réponse au traitement et de pronostic et mérite d'être explorée dans des cohortes plus larges.

\section{Conclusion}

L'analyse de la composition et de la localisation cellulaire par immunofluorescence multiparamétrique en transplantation rénale avec analyse automatisée représente un nouvel outil pour caractériser la réponse allo-immune. Nous pensons que cette technique peut être très intéressante en néphrologie. La démonstration que cette technique peut s'appliquer sur des biopsies fixées et incluses en paraffine permettra d'ouvrir de nouveaux champs de recherche en pathologie rénale.

\section{Conflit d'intérêts}

Aucun

\section{Financements}

Ce travail a été fait grâce à une bourse accordée par l'Agence de la biomédecine (ABM) et par la Fondation pour la recherche médicale (FRM) ( $\mathrm{n}^{\circ}$ DEA20170638449). Nous remercions aussi grandement la fondation Emmanuel-Boussard pour son soutien a la recherche en néphrologie et en transplantation rénale à l'hôpital Necker-Enfants malades.

\section{Remerciements}

Nous remercions Chantal Mandet pour son aide technique précieuse et les laboratoires Innate Pharma pour l'anticorps anti NKp46.

\section{Références}

1. Haas M, Loupy A, Lefaucheur C, Roufosse C, Glotz D, Seron D, et al. The Banff 2017

Kidney Meeting Report: Revised diagnostic criteria for chronic active T cell-mediated rejection, antibody-mediated rejection, and prospects for integrative endpoints for next-generation clinical trials. Am J Transplant 2018;18:293-307. 
2. Lefaucheur C, Loupy A, Vernerey D, Duong-Van-Huyen JP, Suberbielle C, Anglicheau D, et al. Antibody-mediated vascular rejection of kidney allografts: a population-based study. Lancet 2013;381:313-9.

3. Lefaucheur C, Nochy D, Hill GS, Suberbielle-Boissel C, Antoine C, Charron D, et al. Determinants of poor graft outcome in patients with antibody-mediated acute rejection. Am J Transplant 2007;7:832-41.

4. Hancock WW, Thomson NM, Atkins RC. Composition of interstitial cellular infiltrate identified by monoclonal antibodies in renal biopsies of rejecting human renal allografts. Transplantation 1983;35:458-63.

5. Bergler T, Jung B, Bourier F, Kühne L, Banas MC, Rümmele P, et al. Infiltration of macrophages correlates with severity of allograft rejection and outcome in human kidney transplantation. PLoS One 2016;11:e0156900.

6. Brasen JH, Khalifa A, Schmitz J, Dai W, Einecke G, Schwarz A, et al. Macrophage density in early surveillance biopsies predicts future renal transplant function. Kidney Int 2017;92:479-489.

7. Sicard A, Meas-Yedid V, Rabeyrin M, Koenig A, Ducreux S, Dijoud F, et al. Computerassisted topological analysis of renal allograft inflammation adds to risk evaluation at diagnosis of humoral rejection. Kidney Int 2017;92:214-226.

8. Hidalgo LG, Sis B, Sellares J, Campbell PM, Mengel M, Einecke G, et al. NK cell transcripts and NK cells in kidney biopsies from patients with donor-specific antibodies: evidence for NK cell involvement in antibody-mediated rejection. Am J Transplant 2010;10:1812-22.

9. Hidalgo LG, Sellares J, Sis B, Mengel M, Chang J, Halloran PF. Interpreting NK cell transcripts versus $\mathrm{T}$ cell transcripts in renal transplant biopsies. Am J Transplant 2012;12:1180-91.

10. Littera R, Piredda G, Argiolas D, Lai S, Congeddu E, Ragatzu P, et al. KIR and their HLA Class I ligands: Two more pieces towards completing the puzzle of chronic rejection and graft loss in kidney transplantation. PLoS One 2017;12:e0180831.

11. Van Acker HH, Capsomidis A, Smits EL, Van Tendeloo VF. CD56 in the immune system: more than a marker for cytotoxicity? Front Immunol 2017;8:892.

12. Stack EC, Wang C, Roman KA, Hoyt CC. Multiplexed immunohistochemistry, imaging, and quantitation: a review, with an assessment of Tyramide signal amplification, multispectral imaging and multiplex analysis. Methods 2014;70:46-58. 
13. Parra ER, Uraoka N, Jiang M, Cook P, Gibbons D, Forget MA, et al. Validation of multiplex immunofluorescence panels using multispectral microscopy for immune-profiling of formalin-fixed and paraffin-embedded human tumor tissues. Sci Rep 2017;7:13380.

14. Nghiem PT, Bhatia S, Lipson EJ, Kudchadkar RR, Miller NJ, Annamalai L, et al. PD-1 blockade with pembrolizumab in advanced merkel-cell carcinoma. N Engl J Med 2016;374:2542-52.

15. Wu H, Malone AF, Donnelly EL, Kirita Y, Uchimura K, Ramakrishnan SM, et al. Single-cell transcriptomics of a human kidney allograft biopsy specimen defines a diverse inflammatory response. J Am Soc Nephrol 2018;29:2069-2080.

16. Thomas KA, Valenzuela NM, Reed EF. The perfect storm: HLA antibodies, complement, FcgammaRs, and endothelium in transplant rejection. Trends Mol Med 2015;21:319-29.

17. Fedrigo M, Leone O, Burke MM, Rice A, Toquet C, Vernerey D, et al. Inflammatory cell burden and phenotype in endomyocardial biopsies with antibody-mediated rejection (AMR): a multicenter pilot study from the AECVP. Am J Transplant 2015;15:526-34. 


\section{Légende des figures}

Figure 1. Résumé du processus d'immunofluorescence multiparamétrique pour l'analyse de biopsies de patients en situation de rejet d'allogreffe rénale. $a, b$ : les lames des biopsies de greffon rénal fixées et incluses en paraffine sont marquées avec les anticorps anti-NKp46, CD163, CD3 et CD34 puis scannées à l'aide d'une caméra multispectrale ; $\mathrm{:} \mathrm{Les} \mathrm{images} \mathrm{sont} \mathrm{analysées} \mathrm{par} \mathrm{le}$ logiciel d'analyse d'images en trois étapes : segmentation cellulaire (basée sur le marquage des noyaux par le 4',6-diamidino-2-phénylindole [DAPI]), segmentation tissulaire (espace intra- et extravasculaire basée sur le marquage endothélial avec le CD34) et phénotypage cellulaire. Après une période d'entrainement du logiciel, celui ci est capable de quantifier et de localiser automatiquement les cellules NK, macrophages et lymphocytes $\mathrm{T}$.

\section{Figure 2. Validation de la technique d'immunofluorescence multiparamétrique pour l'analyse} de biopsies de patients en situation de rejet d'allogreffe rénale. a : exemple de marquage des cellules NK avec l'anticorps anti-NKp46 en immunohistochimie (IHC) ; b : corrélation entre la densité de cellules NK quantifiée manuellement en immunohistochimie et la densité de NK quantifiée automatiquement par immunofluorescence multiparamétrique (multiplex IF) ; c : corrélation entre les densités cellulaires quantifiées par immunofluorescence multiparamétrique et les scores de Banff relatifs à l'inflammation; $\mathrm{d}$ : corrélation entre les densités cellulaires quantifiées par immunofluorescence multiparamétrique et les niveaux d'expression des acides ribonucléiques messagers (ARNm) de NKp46 et KLRF1 (pour les cellules NK), CD3 et CD25 (pour les lymphocytes Ts), et $C D 14$ et $C D 16$ (pour les monocytes/macrophages) mesurés par polymerase chain reaction (PCR) quantitative en temps réel (RTqPCR). Les densités cellulaires sont exprimées en nombre de cellules par millimètre carré $; * \mathrm{p}<0,05 ; * * \mathrm{p}<0,01 ; * * * \mathrm{p}<0,001$.

Figure 3. Composition cellulaire au cours du rejet d'allogreffe rénale. a : images d'immunofluorescence multiparamétrique au cours du rejet humoral (ABMR) et cellulaire (TCMR). Présence d'inflammation microvasculaire (glomérulite (encadré) et capillarite péritubulaire) au cours d'un rejet humoral et d'inflammation interstitielle au cours d'un rejet cellulaire ; b : densités cellulaires dans les biopsies sans rejet (NR), avec ABMR et TCMR ; $\mathrm{:} \mathrm{proportions} \mathrm{relatives} \mathrm{de} \mathrm{cellules} \mathrm{NK,}$ lymphocytes $\mathrm{T}$ et macrophages dans les biopsies sans rejet, avec rejet humoral ou rejet cellulaire (moyenne \pm SEM). NS : non significatif $*{ }^{*} \mathrm{p}<0,05 ; * * \mathrm{p}<0,01 ; * * \mathrm{p}<0,001$ 
Figure 4. Composition cellulaire dans les compartiments intravasculaires et extravasculaires au cours du rejet d'allogreffe rénale. a : illustration d'un cas de rejet cellulaire (TCMR) représentatif avec présence de lymphocytes T, macrophages and cellules NK dans l' interstitium, mais également dans le compartiment intravasculaire (principalement des lymphocytes T) (flèches) ; b : illustration d'un cas de rejet humoral (ABMR) représentatif avec capillarite péritubulaire composée principalement de lymphocytes T mais également de macrophages et de cellules NK (flèches), on remarque également la présence de cellules inflammatoires dans l'interstitium ; c,d : densité et proportion relative de cellules NK, lymphocytes $\mathrm{T}$ et macrophages dans le compartiment extravasculaire ; e,f : densité et proportion relative de cellules NK, lymphocytes T et macrophages dans le compartiment intravasculaire Les densités cellulaires sont exprimées en nombre de cellules par millimètre carré et les proportions en pourcentages .Les valeurs sont données en moyenne \pm SEM ; *p $<0,05 ; * * \mathrm{p}<0,01 ; * * * \mathrm{p}<0,001$.

Figure 5. Hétérogénéité importante de la composition cellulaire au cours du rejet d'allogreffe rénale. $\mathrm{a}, \mathrm{b}$ : proportion relative de cellules $\mathrm{NK}$, lymphocytes $\mathrm{T}$ et macrophages pour chaque cas de rejet humoral (ABMR) et cellulaire (TCMR); c : image représentative de rejets riches en macrophages (cas de rejet cellulaire $n^{\circ} 6$ et cas de rejet humoral $n^{\circ} 6$ ) et de rejets riches en lymphocytes $T$ (cas de rejet cellulaire $n^{\circ} 20$ et cas de rejet humoral $n^{\circ} 20$ ). 
a IHC with anti-NKp46

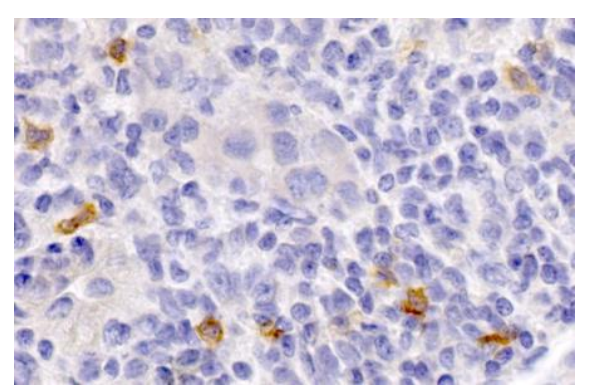

b Correlation between IHC and multiplex IF

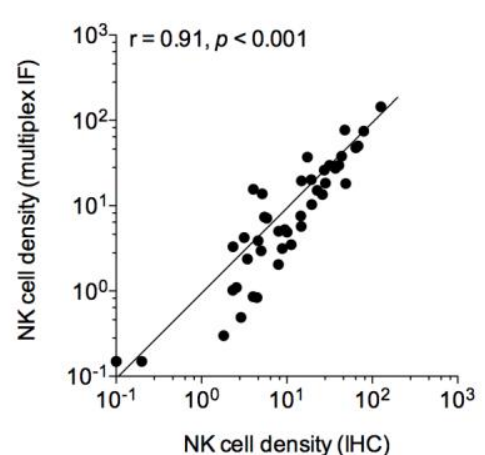

d Correlation between multiplex IF and RT-qPCR
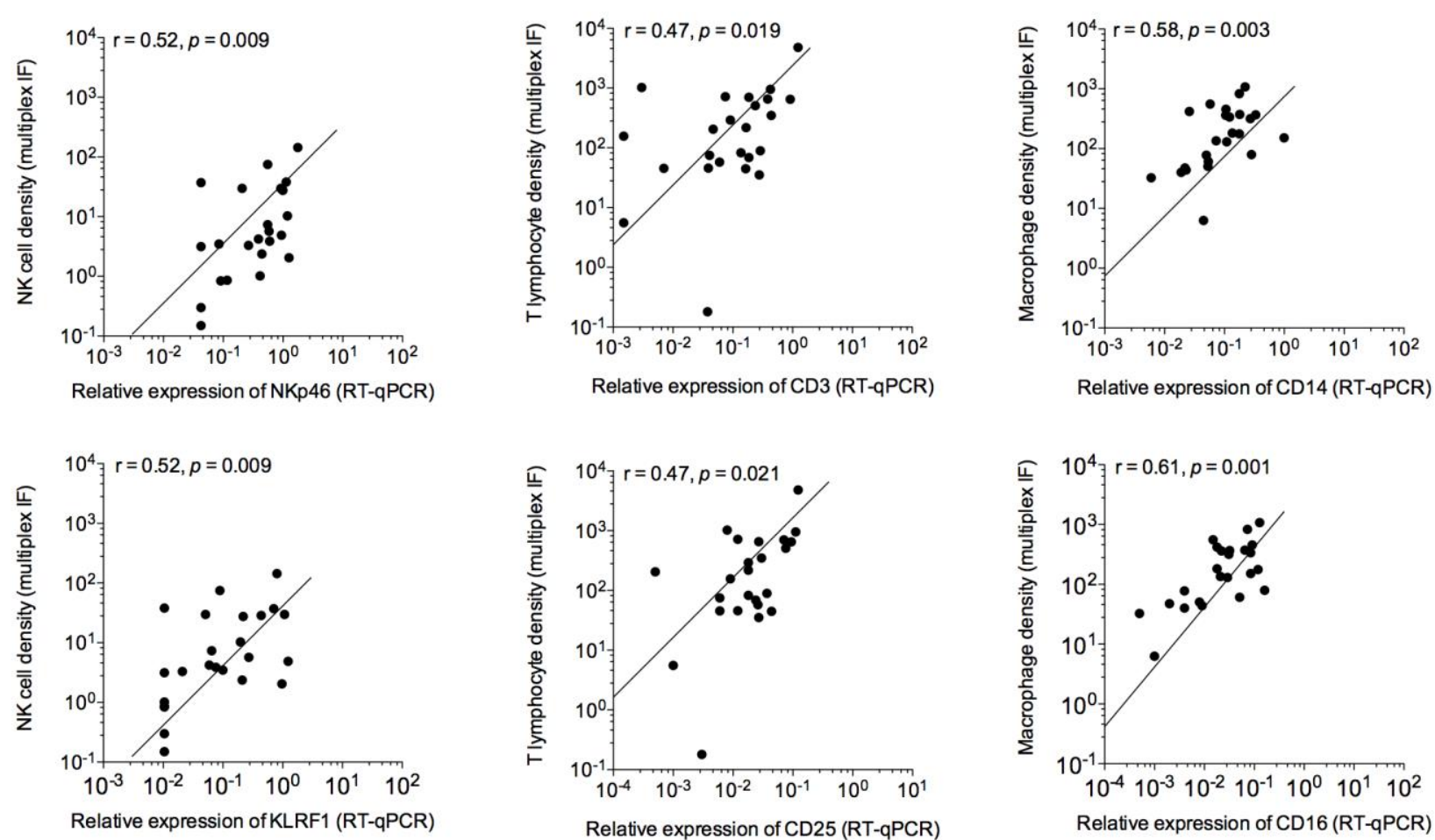

C Correlation between multiplex IF and Banff scores
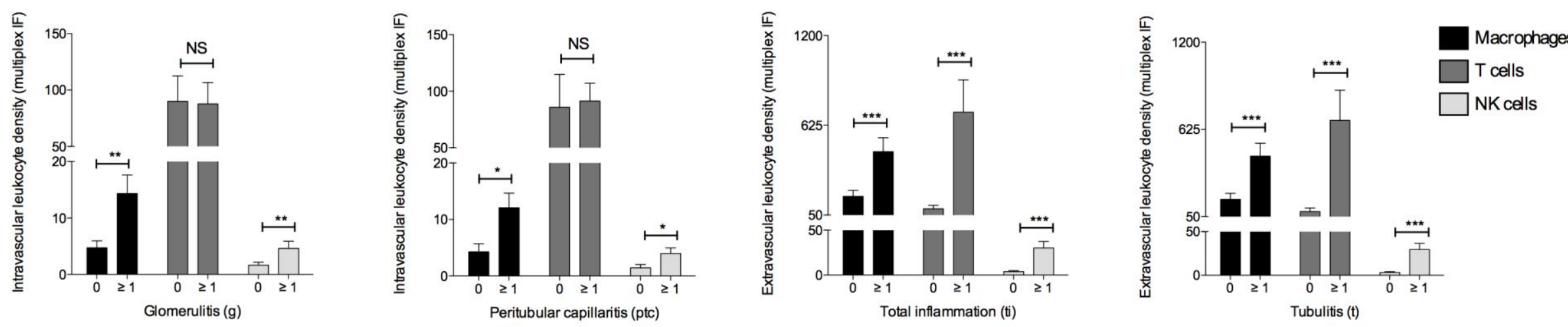
a

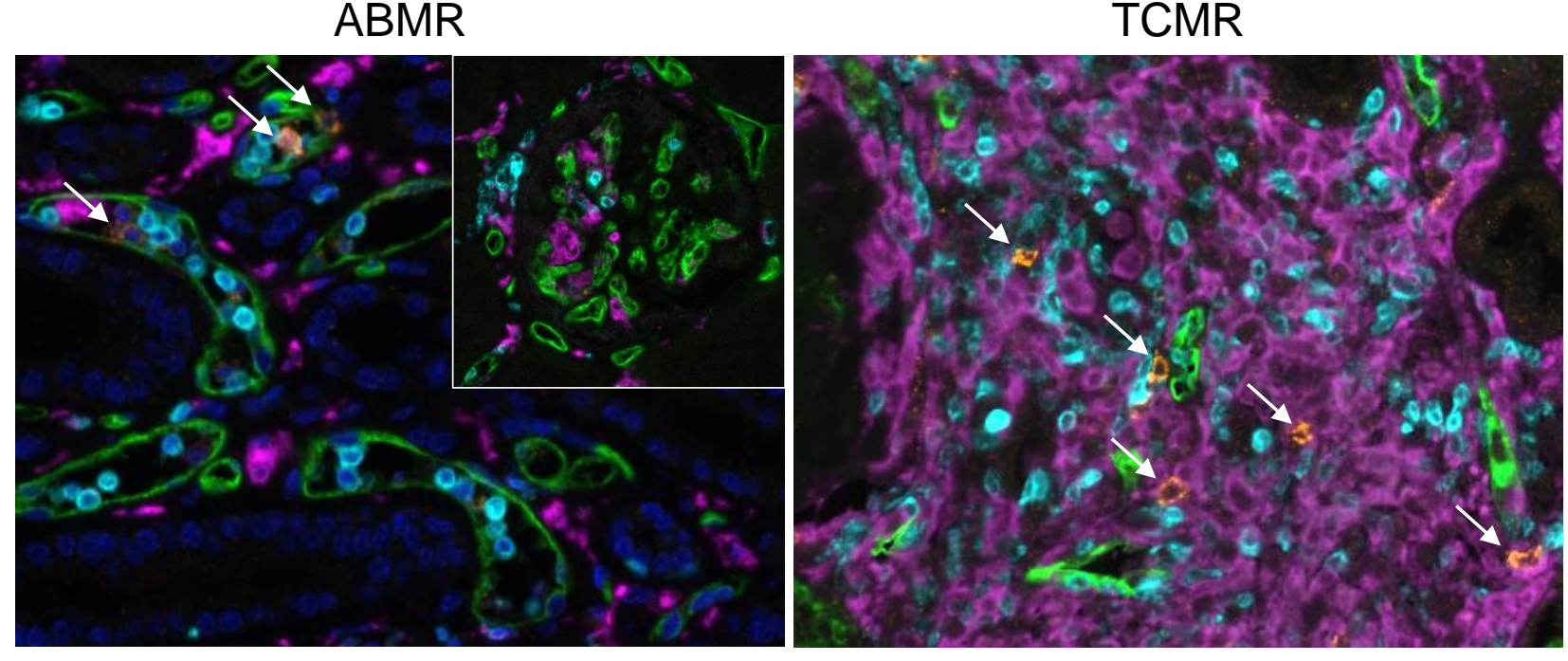

$\square$ NKcells $\square$ T cells $\square$ Macrophages $\square$ Endothelial cells b

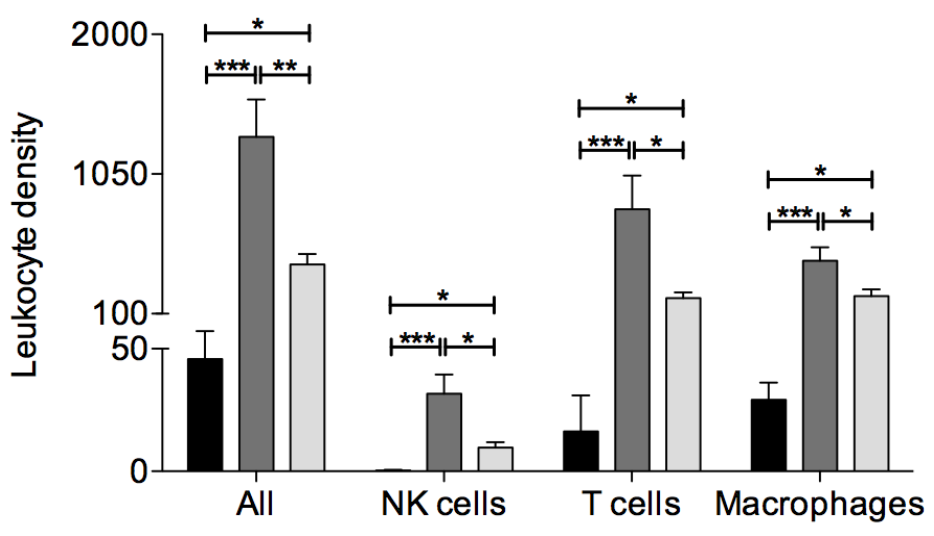

$\square$ NR $\square$ TCMR $\square$ ABMR
C

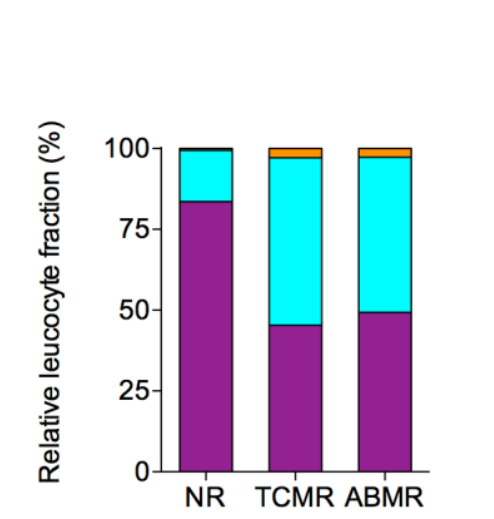

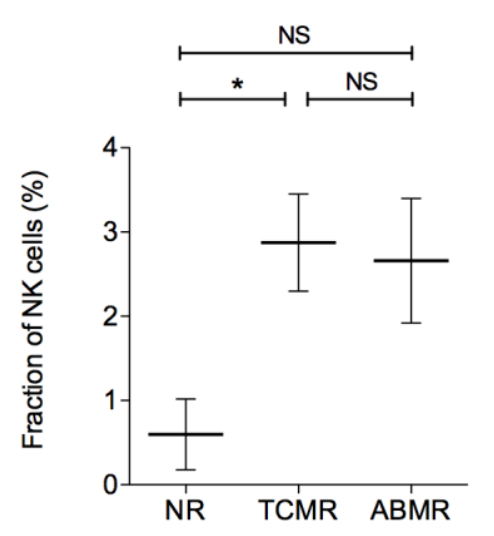
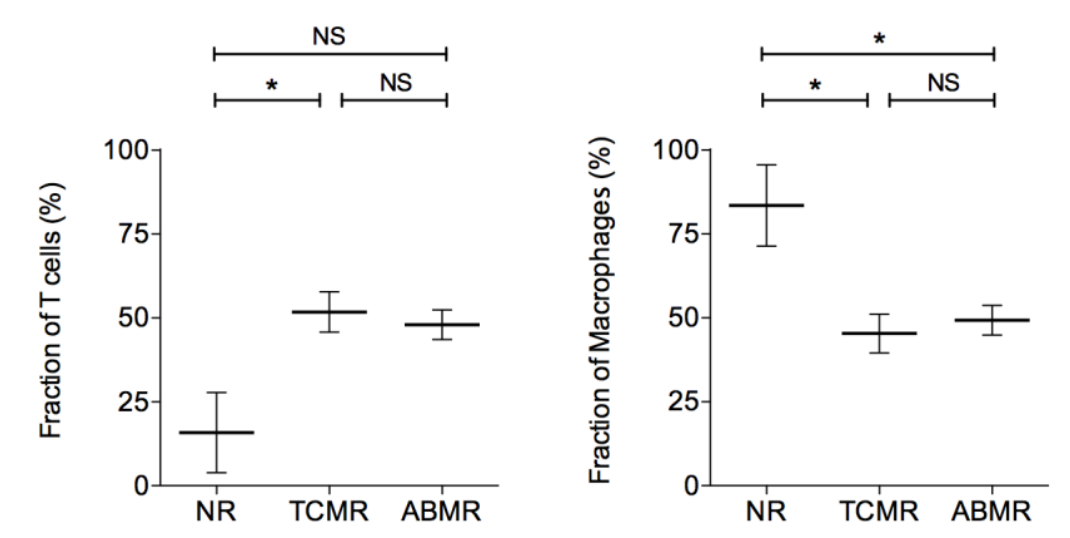

$\square$ NKcells $\square$ T cells $\square$ Macrophages 


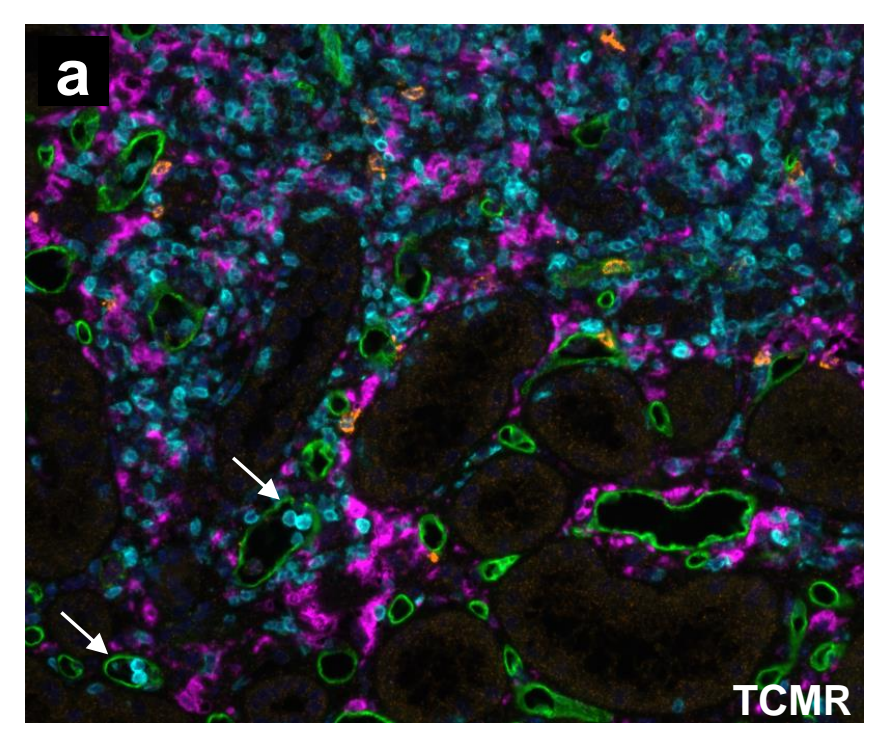

C

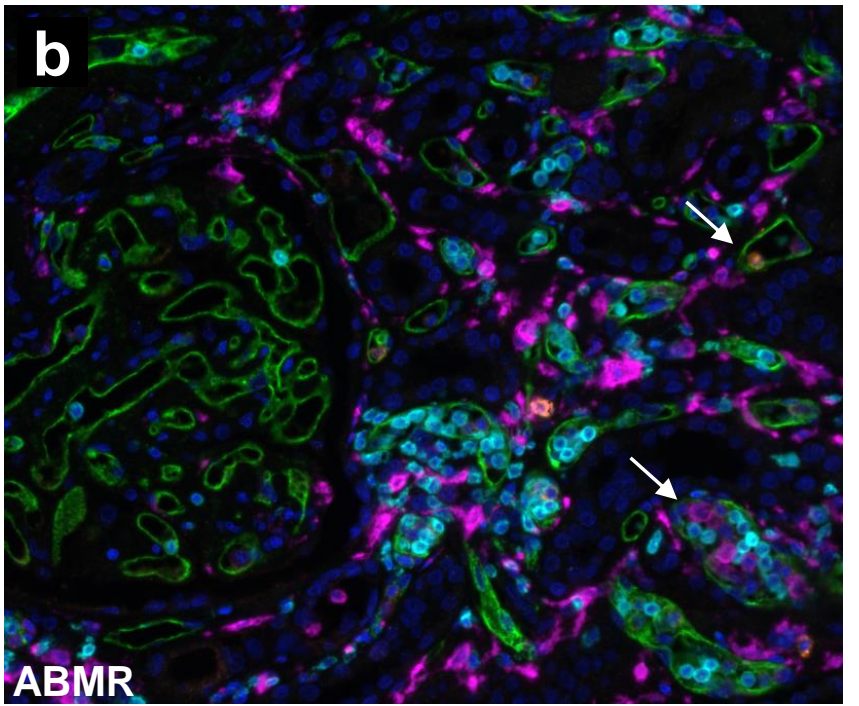

$\square$ NKcells $\square$ T cells $\square$ Macrophages $\square$ Endothelial cells
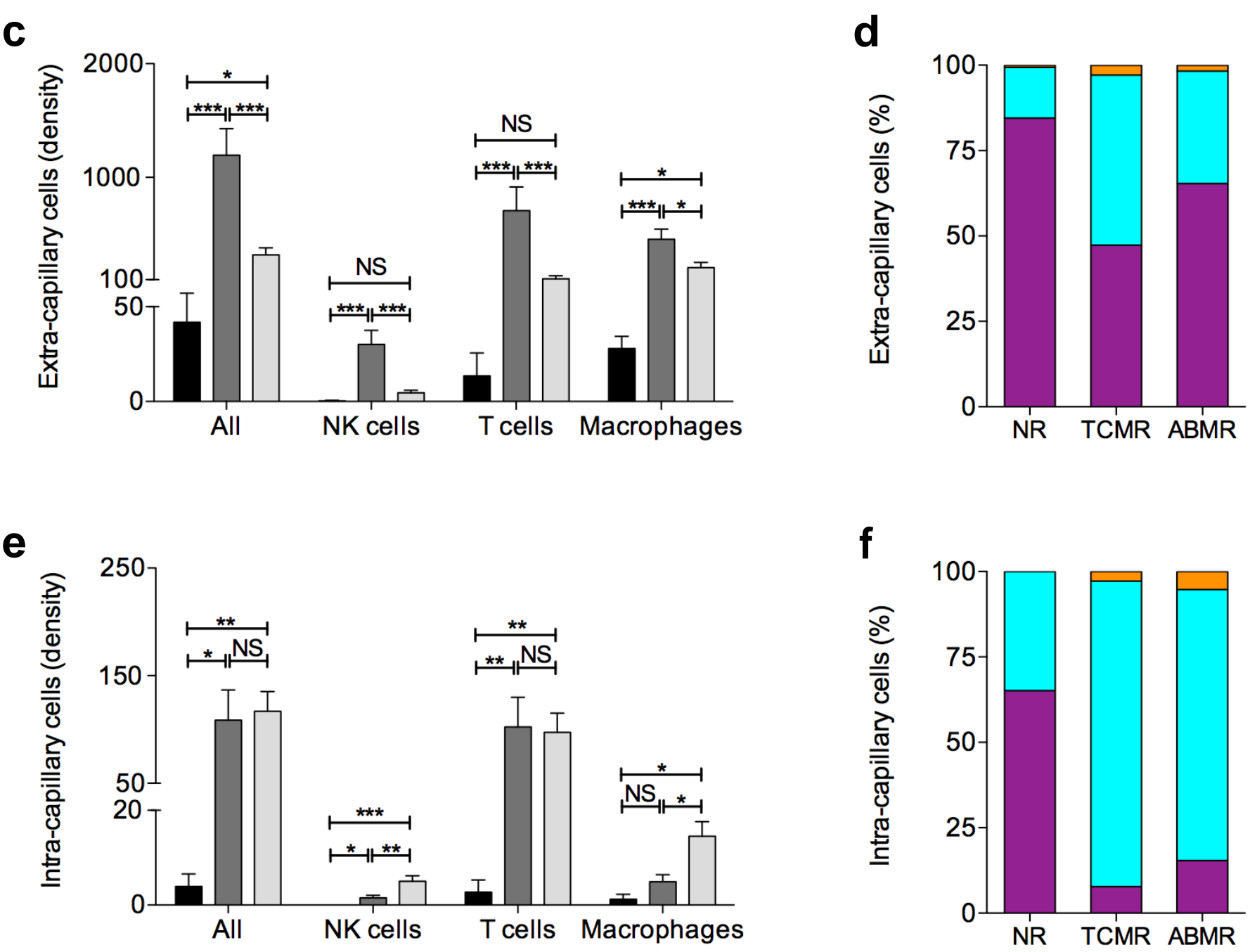

$\square$ NKcells $\square$ T cells $\square$ Macrophages 
a

TCMR

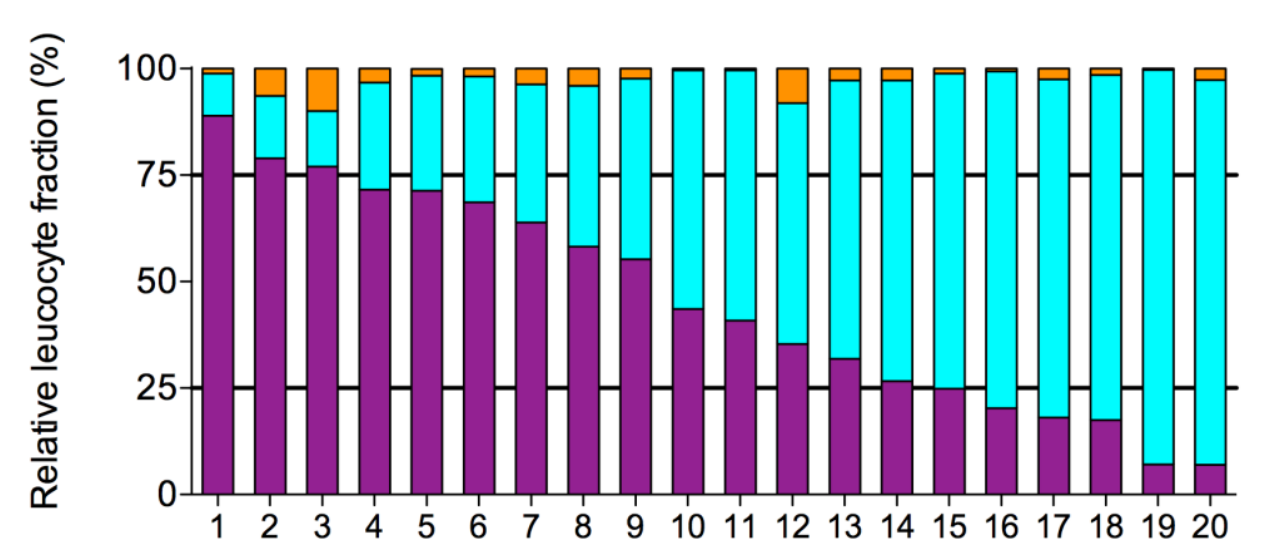

b

ABMR

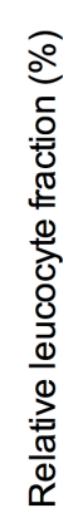

C

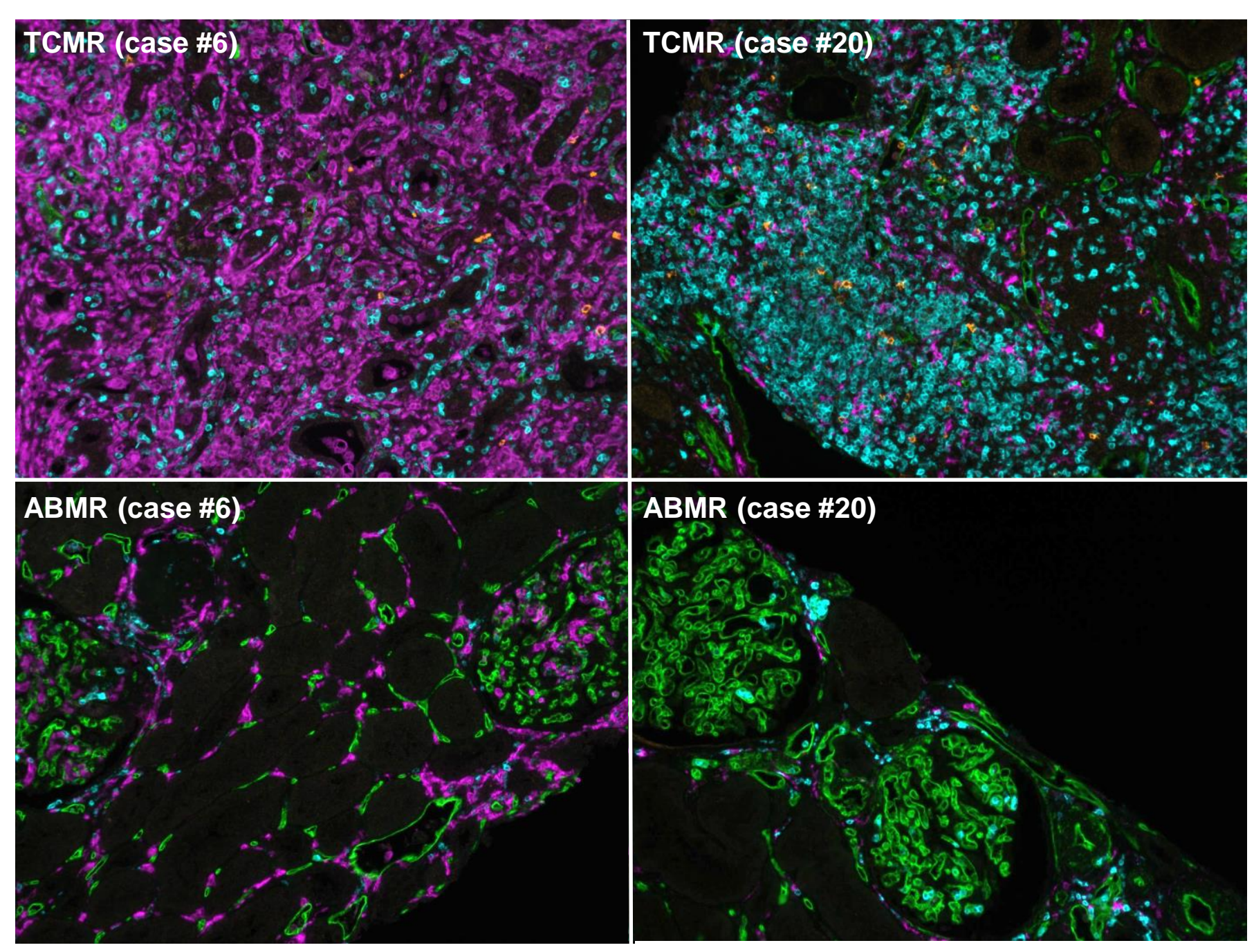


Tableau 1. Analyse des biopsies de patients ayant reçu une greffe de rein : caractéristiques de la population de l'étude.

\begin{tabular}{|c|c|c|c|c|c|}
\hline Variables & $\begin{array}{c}\text { Tous les } \\
\text { patients }(n= \\
44)\end{array}$ & $\begin{array}{c}\text { Pas de rejet }(n \\
=5)\end{array}$ & $\begin{array}{l}\text { Rejet humoral } \\
\qquad(n=20)\end{array}$ & $\begin{array}{c}\text { Rejet } \\
\text { cellulaire }(n= \\
19)\end{array}$ & $p$ \\
\hline \multicolumn{6}{|l|}{ Receveur } \\
\hline$\hat{A g e}^{a}$ & $44,2 \pm 2,9$ ans & $41,4 \pm 11,2$ ans & $47,2 \pm 3,8$ ans & $41,7 \pm 4,7$ ans & 0,63 \\
\hline Sexe masculin & $27(61,4 \%)$ & $2(40,0 \%)$ & $11(55,0 \%)$ & $14(73,7 \%)$ & 0,30 \\
\hline Retransplantation & $4(9,1 \%)$ & $0(0,0 \%)$ & $2(10,0 \%)$ & $2(10,5 \%)$ & 1 \\
\hline \multicolumn{6}{|l|}{ Cause de l'insuffisance rénale terminale } \\
\hline Diabète & $2(4,5 \%)$ & $0(0,0 \%)$ & $1(5,0 \%)$ & $1(5,3 \%)$ & 1 \\
\hline Hypertension & $3(6,8 \%)$ & $0(0,0 \%)$ & $1(5,0 \%)$ & $2(10,6 \%)$ & 0,73 \\
\hline Glomérulopathie & $8(18,2 \%)$ & $0(0,0 \%)$ & $7(35,0 \%)$ & $1(5,3 \%)$ & 0,03 \\
\hline Néphropathie interstitielle & $8(18,2 \%)$ & $3(60,0 \%)$ & $1(5,0 \%)$ & $4(21,0 \%)$ & 0,02 \\
\hline $\begin{array}{l}\text { Maladies } \\
\text { kystiques/héréditaires/congénitale } \\
\mathrm{s}\end{array}$ & $8(18,2 \%)$ & $0(0,0 \%)$ & $4(20,0 \%)$ & $4(21,0 \%)$ & 0,74 \\
\hline Indéterminée & $15(34,1 \%)$ & $2(40,0 \%)$ & $6(30,0 \%)$ & $7(36,8 \%)$ & 0,91 \\
\hline \multicolumn{6}{|l|}{ Donneur } \\
\hline$\hat{A g e}{ }^{a}$ & $44,2 \pm 3,3$ ans & $45,8 \pm 9,6$ ans & $48,1 \pm 4,6$ ans & $39,9 \pm 5,4$ ans & 0,48 \\
\hline Décédé & $33(75 \%)$ & $4(80,0 \%)$ & $14(70 \%)$ & $15(78,9 \%)$ & 1 \\
\hline Donneur à critères élargis ${ }^{b}$ & $9(27 \%)$ & $1(25 \%)$ & $5(36 \%)$ & $3(20 \%)$ & 0,74 \\
\hline \multicolumn{6}{|l|}{ Transplantation } \\
\hline Ischémie froide $^{b}$ & $18,8 \pm 1,5 \mathrm{~h}$ & $15,6 \pm 5,0 \mathrm{~h}$ & $22,0 \pm 1,9 \mathrm{~h}$ & $17,0 \pm 2,2 \mathrm{~h}$ & 0,04 \\
\hline Reprise retardée de fonction & $7(16 \%)$ & $0(0,0 \%)$ & $5(25 \%)$ & $2(10,5 \%)$ & 0,30 \\
\hline \multicolumn{6}{|l|}{ Suivi } \\
\hline Durée de suivi post-transplantation a $^{\text {a }}$ & $53,6 \pm 7,8$ mois & $18,8 \pm 3,1$ mois & $66,0 \pm 15,1$ mois & $49,8 \pm 7,5$ mois & 0,07 \\
\hline
\end{tabular}




\begin{tabular}{|c|c|c|c|c|c|}
\hline Créatininémie au dernier suivi ${ }^{\text {a }}$ & $\begin{array}{c}213,5 \pm 29,2 \\
\mu \mathrm{mol} / \mathrm{L}\end{array}$ & $\begin{array}{c}103,6 \pm 22,7 \\
\mu \mathrm{mol} / \mathrm{L}\end{array}$ & $\begin{array}{c}200,8 \pm 39,3 \\
\mu \mathrm{mol} / \mathrm{L}\end{array}$ & $\begin{array}{c}258,2 \pm 52,5 \\
\mu \mathrm{mol} / \mathrm{L}\end{array}$ & 0,11 \\
\hline $\begin{array}{l}\text { Débit de filtration glomérulaire } \\
\text { estimé }^{\mathrm{b}}\end{array}$ & $\begin{array}{c}47,1 \pm 4,7 \\
\mathrm{ml} / \mathrm{min} / 1,73 \mathrm{~m}^{2}\end{array}$ & $\begin{array}{c}56,5 \pm 10,5 \\
\mathrm{ml} / \mathrm{min} / 1,73 \mathrm{~m}^{2}\end{array}$ & $\begin{array}{c}44,0 \pm 5,0 \\
\mathrm{ml} / \mathrm{min} / 1,73 \mathrm{~m}^{2}\end{array}$ & $\begin{array}{c}48,6 \pm 9,2 \\
\mathrm{ml} / \mathrm{min} / 1,73 \mathrm{~m}^{2}\end{array}$ & 0,58 \\
\hline Protéinurie $^{\mathrm{a}}$ & $\begin{array}{c}0,27 \pm 0,05 \mathrm{~g} / \mathrm{g} \\
\text { créatininurie }\end{array}$ & $\begin{array}{c}0,25 \pm 0,09 \mathrm{~g} / \mathrm{g} \\
\text { créatininurie }\end{array}$ & $\begin{array}{c}0,33 \pm 0,08 \mathrm{~g} / \mathrm{g} \\
\text { créatininurie }\end{array}$ & $\begin{array}{c}0,21 \pm 0,07 \mathrm{~g} / \mathrm{g} \\
\text { créatininurie }\end{array}$ & 0,39 \\
\hline Décès & $1(2,3 \%)$ & $0(0,0 \%)$ & $0(0,0 \%)$ & $1(5,3 \%)$ & 0,55 \\
\hline Retransplantation & $0(0,0 \%)$ & $0(0,0 \%)$ & $0(0,0 \%)$ & $0(0,0 \%)$ & NA \\
\hline Dialyse & $5(11,4 \%)$ & $0(0,0 \%)$ & $2(10,0 \%)$ & $3(15,8 \%)$ & 0,82 \\
\hline
\end{tabular}

a moyenne +/- erreur standard

${ }^{\mathrm{b}}$ pour les donneurs cadavériques

NA : non applicable 
Tableau 2. Analyse des biopsies de patients ayant reçu une greffe de rein : caractéristiques cliniques et biologiques au moment de la biopsie.

\begin{tabular}{|c|c|c|c|c|c|}
\hline Variables & $\begin{array}{c}\text { Toutes les } \\
\text { biopsies }(n= \\
45)\end{array}$ & $\begin{array}{c}\text { Pas de rejet } \\
\quad(n=5)\end{array}$ & $\begin{array}{l}\text { Rejet humoral } \\
\quad(n=20)\end{array}$ & $\begin{array}{c}\text { Rejet } \\
\text { cellulaire }(n= \\
20)\end{array}$ & $p$ \\
\hline \multicolumn{6}{|l|}{ Caractéristiques cliniques et biologiques } \\
\hline Délai post-transplantation $^{\mathrm{a}}$ & $27,6 \pm 7,3$ mois & $4,6 \pm 3,0$ mois & $44,6 \pm 14,7$ mois & $16,5 \pm 5,5$ mois & 0,43 \\
\hline Créatininémie $^{\text {a }}$ & $\begin{array}{c}212,4 \pm 22,2 \\
\mu \mathrm{mol} / \mathrm{L}\end{array}$ & $\begin{array}{c}108,2 \pm 18,5 \\
\mu \mathrm{mol} / \mathrm{L}\end{array}$ & $\begin{array}{c}208,3 \pm 32,7 \\
\mu \mathrm{mol} / \mathrm{L}\end{array}$ & $\begin{array}{c}242,5 \pm 36,0 \\
\mu \mathrm{mol} / \mathrm{L}\end{array}$ & 0,06 \\
\hline $\begin{array}{l}\text { Débit de filtration glomérulaire } \\
\text { estimé }^{\mathrm{b}}\end{array}$ & $\begin{array}{c}41,3 \pm 3,6 \\
\mathrm{ml} / \mathrm{min} / 1,73 \mathrm{~m}^{2}\end{array}$ & $\begin{array}{c}64 \pm 14,4 \\
\mathrm{ml} / \mathrm{min} / 1,73 \\
\mathrm{~m}^{2}\end{array}$ & $\begin{array}{c}38,3 \pm 4,7 \\
\mathrm{ml} / \mathrm{min} / 1,73 \mathrm{~m}^{2}\end{array}$ & $\begin{array}{c}38,6 \pm 5,1 \\
\mathrm{ml} / \mathrm{min} / 1,73 \mathrm{~m}^{2}\end{array}$ & 0,19 \\
\hline \multicolumn{6}{|l|}{ Immunologie } \\
\hline $\begin{array}{l}\text { Anticorps spécifiques du donneur } \\
\text { à la biopsie }\end{array}$ & $21(46,6 \%)$ & $1(20,0 \%)$ & $13(65,0 \%)$ & $7(35,0 \%)$ & 0,07 \\
\hline $\begin{array}{l}\text { Anticorps spécifiques du donneur } \\
\text { de classe I }\end{array}$ & $6(13,3 \%)$ & $1(20,0 \%)$ & $2(10,0 \%)$ & $3(15,0 \%)$ & 0,23 \\
\hline $\begin{array}{l}\text { Anticorps spécifiques du donneur } \\
\text { de classe II }\end{array}$ & $11(24,4 \%)$ & $0(0,0 \%)$ & $8(40,0 \%)$ & $3(15,0 \%)$ & 0,12 \\
\hline $\begin{array}{l}\text { Anticorps spécifiques du donneur } \\
\text { de classes I et II }\end{array}$ & $4(8,9 \%)$ & $0(0,0 \%)$ & $3(15,0 \%)$ & $1(5,0 \%)$ & 0,76 \\
\hline $\begin{array}{l}\text { Intensité de fluorescence de } \\
\text { l'anticorps spécifiques du } \\
\text { donneur immunodominant }\end{array}$ & $3074,9 \pm 908,6$ & $299,4 \pm 299,4$ & $4549,5 \pm 1637,5$ & $2289,2 \pm 1160,0$ & 0,08 \\
\hline \multicolumn{6}{|l|}{ Caractéristiques histologiques } \\
\hline Surface de la biopsie $^{a}$ & $4,7 \pm 0,3 \mathrm{~mm}^{2}$ & $4,2 \pm 0,8 \mathrm{~mm}^{2}$ & $4,7 \pm 0,4 \mathrm{~mm}^{2}$ & $4,9 \pm 0,6 \mathrm{~mm}^{2}$ & 0,81 \\
\hline Nombre de glomérules ${ }^{\text {a }}$ & $11,3 \pm 0,9$ & $12,6 \pm 5,0$ & $11,3 \pm 1,2$ & $11,0 \pm 1,2$ & 0,90 \\
\hline \multicolumn{6}{|l|}{ Scores de Banff ${ }^{\text {a }}$} \\
\hline Glomérulite (g) & $0,8 \pm 0,1$ & $0,2 \pm 0,2$ & $1,7 \pm 0,2$ & $0 \pm 0,0$ & $<0,001$ \\
\hline Capillarite péritubulaire (cpt) & $1,3 \pm 0,2$ & $0 \pm 0,0$ & $2,3 \pm 0,1$ & $0,6 \pm 0,2$ & $<0,001$ \\
\hline Inflammation interstitielle (i) & $0,9 \pm 0,2$ & $0 \pm 0,0$ & $0 \pm 0,0$ & $2,1 \pm 0,2$ & $<0,001$ \\
\hline
\end{tabular}




\begin{tabular}{|l|c|c|c|c|c|}
\hline Tubulite (t) & $1,4 \pm 0,2$ & $0 \pm 0,0$ & $0,2 \pm 0,2$ & $2,9 \pm 0,1$ & $<0,001$ \\
\hline Inflammation totale (ti) & $1,0 \pm 0,2$ & $0 \pm 0,0$ & $0 \pm 0,0$ & $2,4 \pm 0,1$ & $<0,001$ \\
\hline Artérite intimale (v) & $0,2 \pm 0,1$ & $0 \pm 0,0$ & $0,3 \pm 0,2$ & $0,1 \pm 0,1$ & 0,37 \\
\hline $\begin{array}{l}\text { Fibrose interstitielle et atrophie } \\
\text { tubulaire (IF/TA) }\end{array}$ & $0,7 \pm 0,2$ & $0 \pm 0,0$ & $0,8 \pm 0,2$ & $0,9 \pm 0,3$ & 0,21 \\
\hline C4d & $0,6 \pm 0,2$ & $0 \pm 0,0$ & $1,2 \pm 0,3$ & $0,3 \pm 0,1$ & 0,03 \\
\hline
\end{tabular}

NA : non applicable

${ }^{\text {a }}$ moyenne $+/$ - erreur standard.

${ }^{\text {b }}$ calculé avec la formule de la Chronic Kidney Disease Epidemiology Collaboration (CKD-EPI) ou la formule de Schwartz en fonction de l'âge du patient au moment de la biopsie. 